
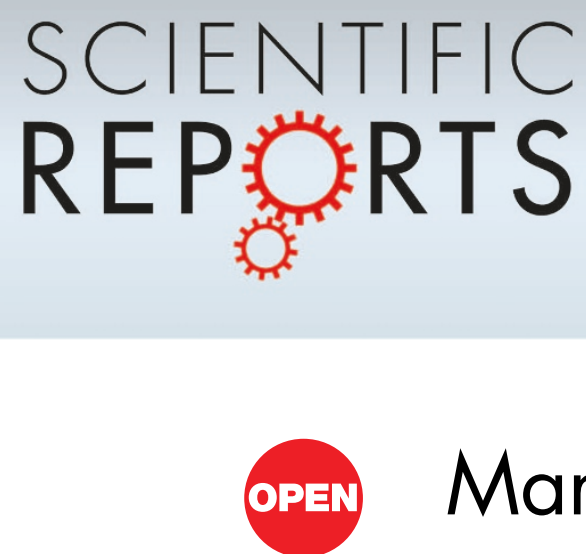

\title{
Man made deltas
}

\author{
Vittorio Maselli \& Fabio Trincardi
}

SUBJECT AREAS:

GEOMORPHOLOGY

PALAEOCLIMATE

CLIMATE-CHANGE IMPACTS

GEOLOGY

Received

6 March 2013

Accepted

16 May 2013

Published

31 May 2013

Correspondence and requests for materials should be addressed to

V.M. (vittorio.maselli@

bo.ismar.cnr.it)
Istituto di Scienze Marine, ISMAR-CNR, Via Gobetti 101, Bologna, Italy.

The review of geochronological and historical data documents that the largest southern European deltas formed almost synchronously during two short intervals of enhanced anthropic pressure on landscapes, respectively during the Roman Empire and the Little Ice Age. These growth phases, that occurred under contrasting climatic regimes, were both followed by generalized delta retreat, driven by two markedly different reasons: after the Romans, the fall of the population and new afforestation let soil erosion in river catchments return to natural background levels; since the industrial revolution, instead, flow regulation through river dams overkill a still increasing sediment production in catchment basins. In this second case, furthermore, the effect of a reduced sediment flux to the coasts is amplified by the sinking of modern deltas, due to land subsidence and sea level rise, that hampers delta outbuilding and increases the vulnerability of coastal zone to marine erosion and flooding.

D eltas are strongly three-dimensional lithosomes that represent one of the most complex, fragile and densely populated landscapes of mid-latitude modern coastal systems. Understanding the life cycle of modern deltas since their embryonic stages is crucial for disentangling the role of natural vs. anthropic forcing, an open issue that bears substantial implications on our full awareness on the management of the entire coastal zone. By underpinning the timing of the main phases of delta growth it is possible to define how pervasively have human populations modified landscapes and to predict threats to delta stability during forthcoming, and possibly abrupt, environmental changes. The growth of deltas reflects the forcing by eustatic oscillations, which determines the available space for sediment accumulation, the riverine input, defined by water and sediment discharge, and the oceanographic regime, responsible for sediment dispersal ${ }^{1}$. The lithology and morphology of the drainage basin and the climatic regime govern sediment production and delivery to the coast, while the power of marine processes (storms, waves and tides) and local vertical movements of the delta plain controls sediment accumulation and the final shape of the delta ${ }^{2}$.

The evolution of modern deltas can be reconstructed combining complementary information from multiproxy analyses, at core scale, and from geomorphological reconstructions of the growth of delta plains, channel avulsion and delta lobe progradations ${ }^{3}$. The comparative study of the Ebro, Rhone, Po and Danube deltas, representing the four main deltas of the northern Mediterranean and Black Sea regions (Fig. 1), is favored by the following circumstances: 1 - the oceanographic regime of the receiving basins has allowed delta formation and substantial preservation; 2- the four catchments present comparable climate conditions having contiguous watersheds (comprised between $40^{\circ}$ and $48^{\circ} \mathrm{N}$ ) impacted by human diffusion since the Neolithic; 3 - the ages of the main progradation phases are constrained by robust chronologies, also supported by map documentations over the last 5 centuries, providing the possibility to establish reliable trans-delta time lines. The comparison of the evolution of northern Mediterranean and Black Sea deltas, permits a super-regional correlation of their growth/ retreat phases; this approach to the study of modern deltas allows understanding the relative role of climate forcing and of growing human population in their evolution.

To identify the intervals of maximum rate of delta outbuilding and to attempt a chronologically constrained comparison of phases of accelerated delta growth among different systems, it is useful to simplify the threedimensional progradation of each individual lobe and to convert it into "spatially-averaged" linear values (Supplementary S1), quantifying also the evolution of the paleoenvironmental constraints (climate, relative sea level and oceanography, Supplementary S2). In this way it is possible to identify synchronous changes in the rates of delta growth that may reflect anthropic perturbations of the natural landscapes, likely in response to the spread of new techniques in forest clearance, cropland cultivation, or urbanization. By comparing the linear rates of delta front progradation (Fig. 2, Supplementary S3) we differentiate the impact of Mid-Late Holocene high-frequency climatic oscillations from that of increasing human population on sediment production and, ultimately, delta construction and preservation. 


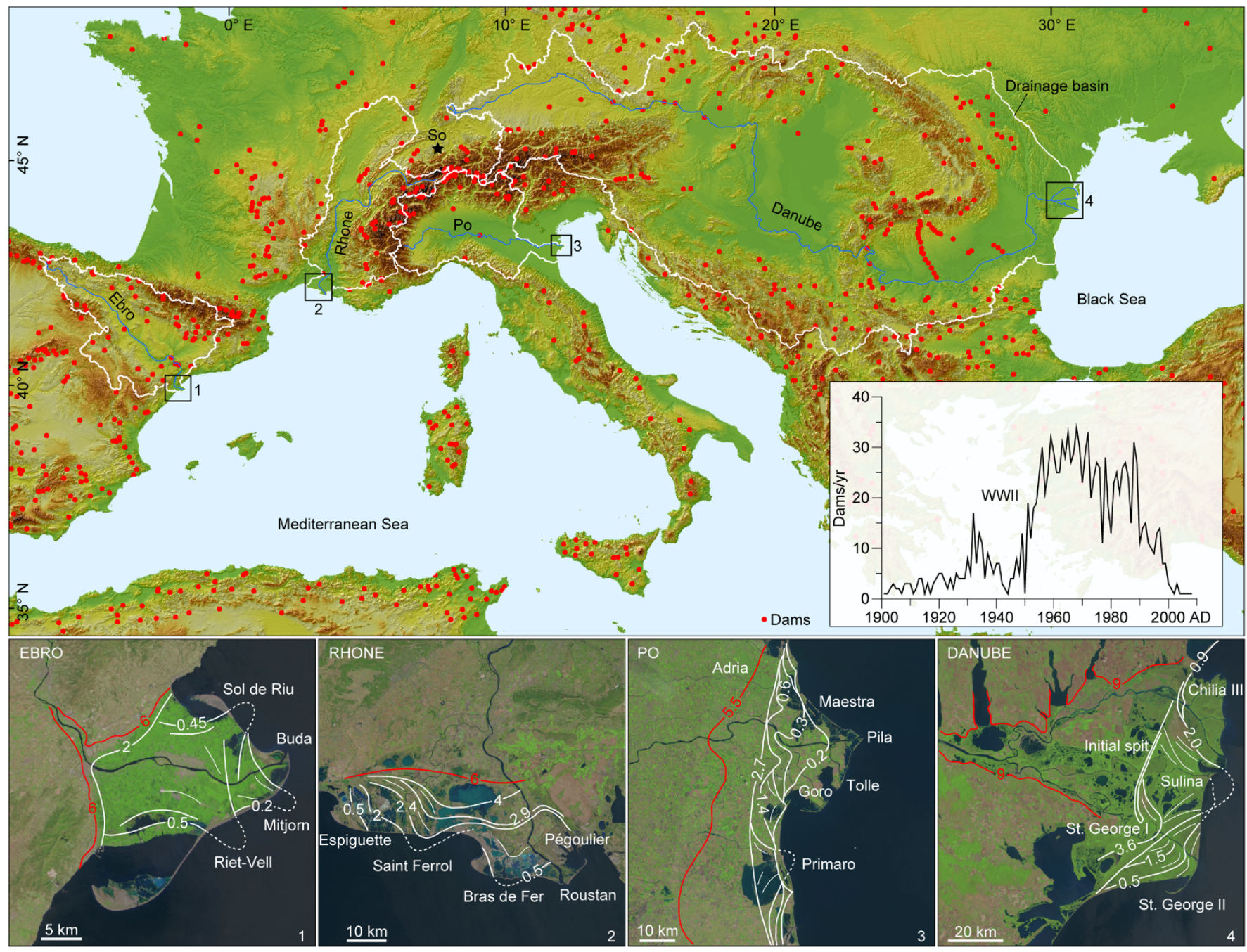

Figure 1 Location of the four delta systems with catchments and growth phases. Drainage basins of the largest southern European river systems on SRTM 90 m Digital Elevation Data (CGIAR-CSI), with major dams and reservoirs (red dots) and location of the Soppensee Lake (black star; see pollen spectra in Figure 3). The inset graph shows the number of river dams built per year since 1900 AD; the temporary decline in dam construction in the ' 40 can be attributed to the Second World War (see Supplementary S5). Below: satellite views of modern deltas (from the Landsat Archive and the Global Land Survey), with red lines representing their embryonic stages, during the last phases of post-glacial sea level rise (between 9 and $5.5 \mathrm{kyr}$ BP), and the white lines representing the main dated progradational events of delta growth (see Supplementary S3).

\section{Results}

Delta growth, climate and humans. The onset of the northern Mediterranean and Black Sea deltas follows an ancestral phase dominated by estuary fill and relatively slow delta growth, that can be traced back to the Mid-Holocene (Fig. 2), around $6 \mathrm{kyr}$ BP, when deceleration in the rate of sea level rise allowed sediment accumulation at the river mouths ${ }^{4,5}$. The following few thousand years of delta growth reflect a complex picture of high frequency climatic changes ${ }^{6}$ accompanied by the spreading of human populations ${ }^{7}$, impacting the land cover, the hydrological cycle and ultimately the sediment production and transport through river catchments (Fig. 3). During the last $3 \mathrm{kyr}$, in particular, a strong relation was observed between the fall of past civilizations and environmental changes driven by climatic deterioration ${ }^{8}$. In Europe the first important human diffusion dates back to the Late Iron Age and continues until the first few centuries $\mathrm{AD}$, as testified by the increased deforestation for construction activities ${ }^{9}$. Extensive tree ring-based reconstructions over central Europe show that this interval was characterized by mild climatic conditions, with summer temperatures and precipitations substantially above average 9 . This evidence is supported by high values in Greenland surface temperature and by a persistent positive North Atlantic Oscillation (NAO) index ${ }^{10,11}$. The rise of classical civilizations and the spread of agricultural activities led to an increase in population and to significant deforestation in central and western Europe ${ }^{12}$. The peak of human growth was reached at the apex of the Roman Empire around $250 \mathrm{yr} \mathrm{AD}^{12}$, which corresponds also to the first hemispheric-scale pollution event caused by metal extraction and production ${ }^{13}$. This important anthropic control on the natural environment at European scale resulted in a substantial increase of soil erosion and in the first major burst in the outbuilding of river-dominated deltas that interrupted, around $0 \mathrm{AD}$, the previous phase of slower strand plain construction. The expansion of human populations across central Europe during the six centuries of the Roman Empire was accompanied by marked modifications of landscapes, with forest clearance and land-use changes for cropland and pasture; these changes resulted in a huge increase in sediment production in the river watersheds that led to the first synchronous accelerated phase of Pan-Mediterranean delta construction (Fig. 2). During this interval several roman harbors were rapidly mud-filled in response to enhanced river run off and increased sediment load ${ }^{14}$.

The main environmental signature of the fall of the Roman Empire, at the end of the $4^{\text {th }}$ century, is the new afforestation, also 

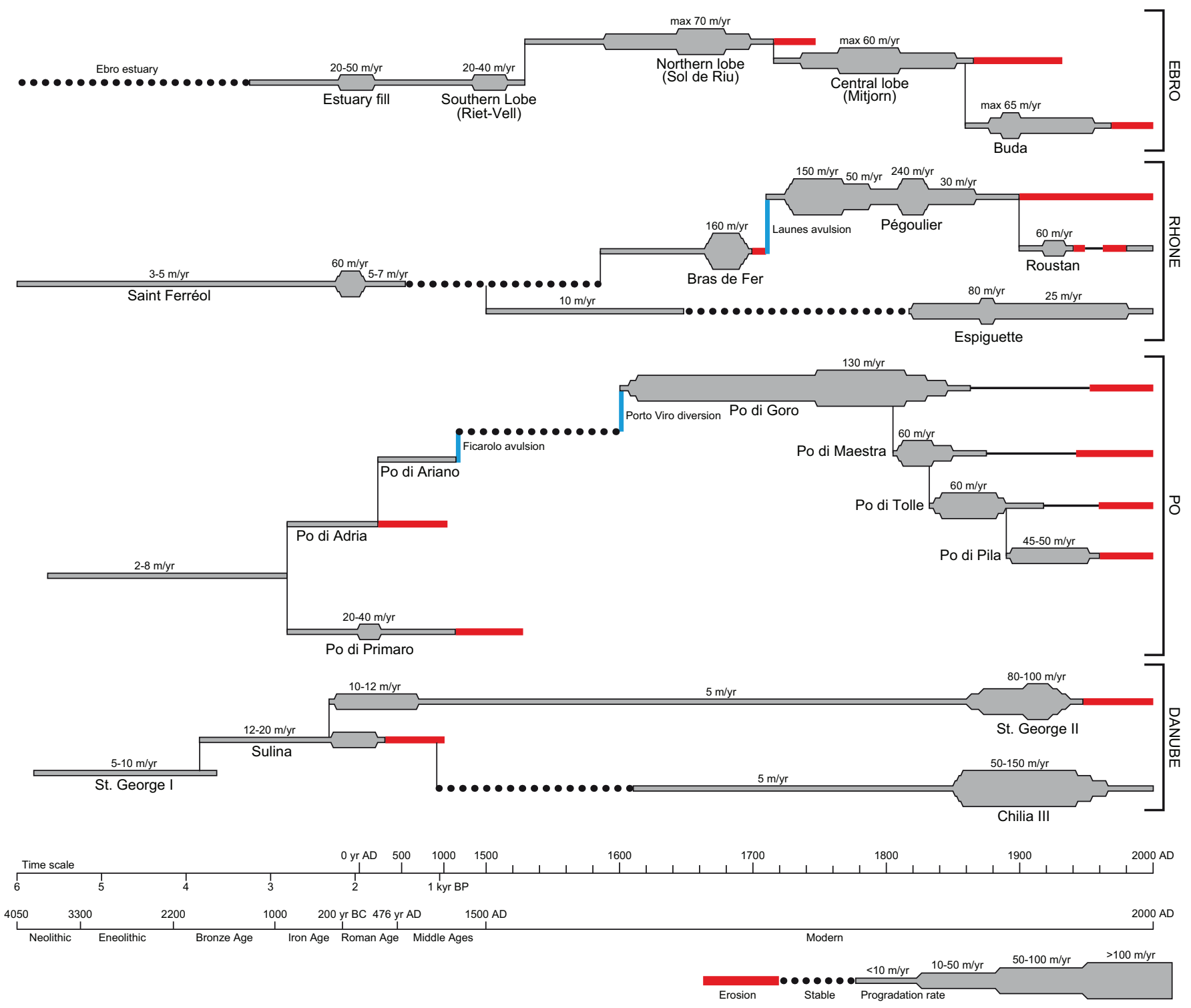

Figure $2 \mid$ Correlation of linear progradation rates of the four delta systems. Summary of the main intervals of delta growth of the Ebro, Rhone, Po and Danube systems, reporting their maximum rates as orders of magnitude (see Supplementary S1 and S3). Note that the time window is in two scales with 1 kyr steps, before $1500 \mathrm{AD}$, and $20 \mathrm{yr}$ steps, onwards; delta growth rates are also summarized against a linear time scale in Figure 3 . Two major and substantially synchronous phases of delta construction correspond to the expansion from $300 \mathrm{yr} B C$ to $250 \mathrm{yr} \mathrm{AD}$, and the last ca. four centuries, matching the Little Ice Age. Retreat of major delta fronts occurred after the Roman Empire and impacted almost all delta lobes during the last 50 yr (red bars).

simulated by the HYDE model for central Europe ${ }^{12,15}$; this afforestation reflects a substantial reduction in the number of inhabitants in response of the barbarian invasions during the Migration Period $\left(5^{\text {th }}-9^{\text {th }}\right.$ centuries AD), accompanied by an overall decrease of air temperatures, as indicated also by pollen spectra from the Switzerland Alps (Fig. 3). All the southern European deltas show a generalized retreat during the millennium following the decline of the Roman Empire; this interval encompassed repeated climate oscillations, including the cold Dark Ages and the Medieval Climate Anomaly (MCA) that was accompanied by a gradual socioeconomic consolidation with a consistent demographic growth. The MCA, a 250-yr period of climatic amelioration, shows a closely-spaced succession of warm and wet summers that favoured population growth and consequent forest clearance for cropland and pasture. NAO index reconstructions ${ }^{16}$ show a prolonged positive state during the $\mathrm{MCA}^{17}$ that favored a period of increased river discharge reflecting enhanced precipitations and retreat of Alpine glaciers ${ }^{18}$. One outcome of this trend was the major avulsion phase of Ficarolo in the Po River Delta (1152 AD; Fig. 2 and 3).

A first cold spell around $1300 \mathrm{AD}$ marked the transition from the MCA to the Little Ice Age (LIA, 1400-1850 AD) when the deterioration of climatic conditions prepared the ground for the pandemic diffusion of the Black Death from (1347-1350 AD), that caused a 60\% reduction in European population that was accompanied by a new major phase of afforestation ${ }^{12}$. The European population returned to pre-pandemic conditions only around the second half of $1400 \mathrm{AD}$ and has increasingly grown ever since.

The LIA marked a dominant reorganization of large-scale atmospheric and oceanic circulation patterns, as highlighted by a typically negative and more variable $\mathrm{NAO}$ index ${ }^{11,16}$. In central and southern Europe, climatic deterioration entailed a strong reduction in temperature and precipitation, with a decrease in winter temperature up to $0.5^{\circ} \mathrm{C}$, that led to several phases of Alpine glacier expansion and 20$50 \mathrm{~mm}$ negative anomalies in precipitation ${ }^{16,19}$, with consequent 


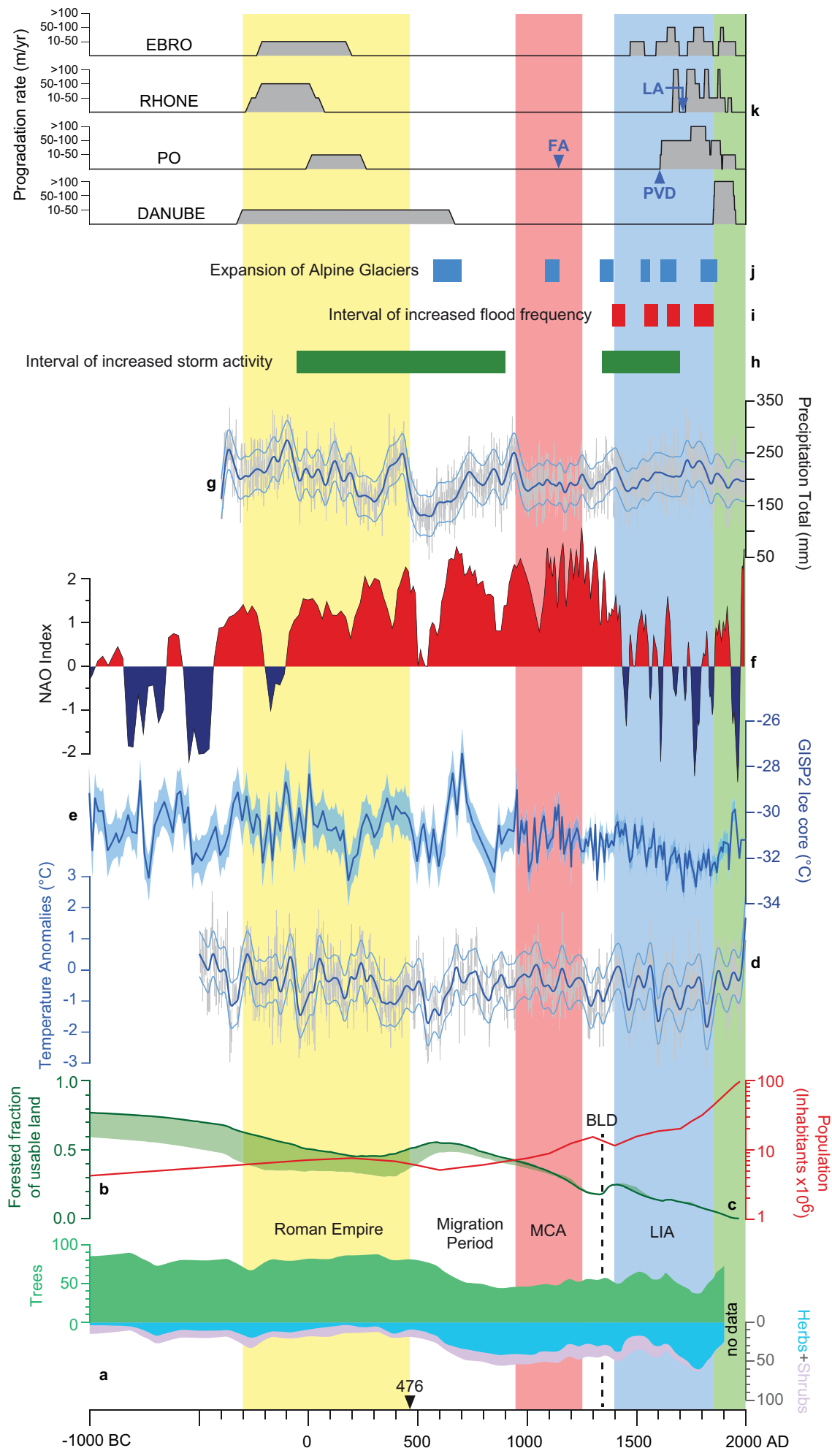

Figure 3 Multi-proxy reconstructions of climate change, human diffusion and delta progradation. The last 3 millennia were characterized by several climatic oscillations, synchronous at northern Hemisphere scale, with two major extremes in the Medieval Climate Anomaly (MCA) and the Little Ice Age (LIA). The trend of pollen record from the central Alps ${ }^{30}$ reflects temperature and precipitation changes all over the Europe region ${ }^{9}$ and can be compared with the temperature record derived from Greenland ice core ${ }^{10}$. Growth rates of the main four northern Mediterranean and Black Sea river deltas (see Supplementary S1, each step is one order of magnitude) increased during the Roman Empire, and dramatically since the onset of the Little Ice Age (LIA), characterized by closely-spaced intervals of advancing and waning of Alpine Glaciers ${ }^{19}$, increased flood frequency ${ }^{23}$, high storm activity ${ }^{31}$, but only a slight increase of total precipitation ${ }^{9}$. These natural factors may reflect the occurrence of repeated and closely spaced NAO-index anomalies $\left({ }^{11}\right.$, positive, red, and negative, blue) and several centuries of overall decreasing $\mathrm{T}^{10}$. While human expanded, in the past, during intervals of milder climate (Roman Empire), this was the first substantially cooler interval severely impacted by humans through, inter alia, forest clearance ${ }^{12}$, increasing population ${ }^{12}$ and related land consumption. The change in land use is well reflected by increased shrub +herb vs. tree in pollen spectra both in the alpine region and in the Mediterranean, especially in the second half of the LIA. 


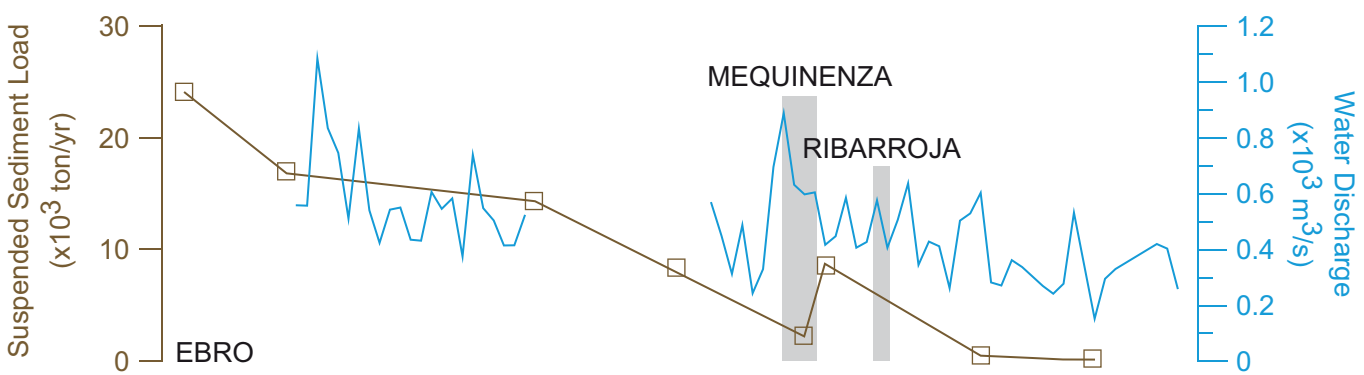

DONZERE-MONDRAGON
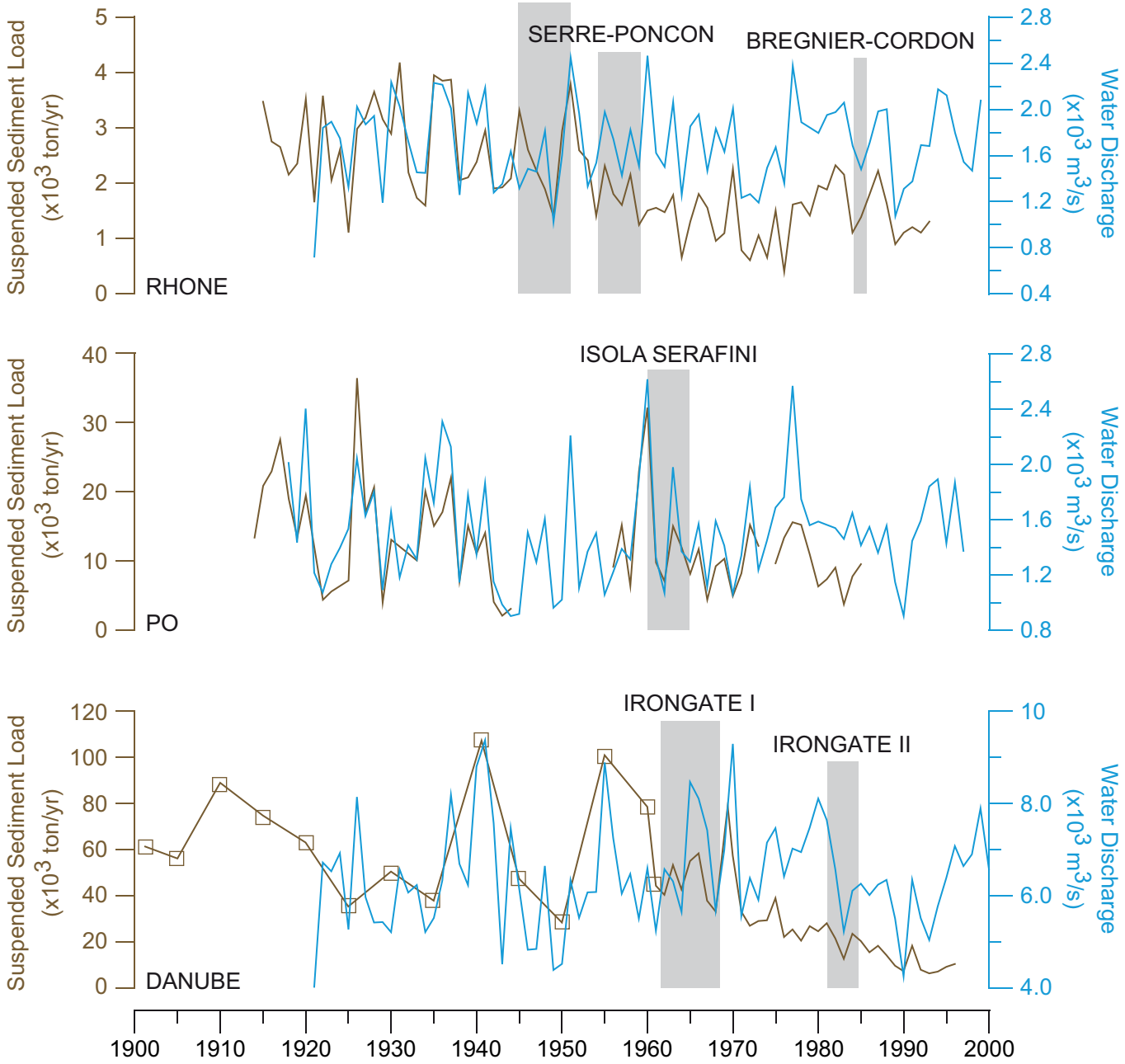

Figure $4 \mid$ Modern water and sediment flux. Coupled diagram of suspend sediment load (brown) and fresh water (light blue) demonstrating the impact of anthropic reservoirs on river discharge in all four Mediterranean deltas; gray stripes highlight the timing of construction of major dams (Supplementary S3 and S5). Peaks of water discharge are in phase with peaks in suspended sediment load only before dam's construction until the '60.

changes in soil vegetation cover ${ }^{20}$. By the second half of the $17^{\text {th }}$ century, roughly corresponding to the beginning of the Maunder Minimum (1645-1715 AD), a new period of delta growth started and continued for the entire LIA and 50 yr beyond. The climatic conditions during the Maunder Minimum, the coldest phase of the LIA, seem to be similar, although less amplified, to those during the Last Glacial Maximum ${ }^{21}$. Interestingly, the LIA had less dramatic impact on human societies with respect to previous intervals of climatic deterioration, because the population had become less vulnerable to climatic fluctuations thanks to technological developments, urbanization and industrialization. In this period, the growth of human population is the main driver for anthropogenic changes in land use and land cover at the expenses of natural forests. $\mathrm{Hu}$ man population has grown exponentially since the XIX century, demanding more usable land for food, fuel and construction; all together, these factors lead to a generalized land-use change at European scale. The resulting regional modifications in hydrology and climate, through changes in albedo, surface roughness, runoff and groundwater storage ${ }^{22}$, determined a dramatic increase in sediment production, sustaining a major and synchronous progradational phase of all the southern European deltas (Fig. 2 and 3). This extremely enhanced sediment production due to anthropic activities was also reinforced by the occurrence of major flood events, connected to increased storm frequency and Alpine glacier collapse $\mathrm{e}^{23}$. In the interval between 1650 and $1900 \mathrm{AD}$, in particular, sediment supplied by all rivers allowed substantial construction of delta plain in each system, and up to $350 \mathrm{~km}^{2}$ for the Po River delta, with rates of linear basinward delta progradation up to $250 \mathrm{~m} / \mathrm{yr}$ (Fig. 1 and 2). 
The last century: deltas and the industrial era. Since the beginning of the Industrial Revolution, human control on the natural environment became overwhelming: at present one-third to onehalf of land surface has been impacted and transformed by human activities $^{24}$, with dramatic perturbations of global ecosystems. The anthropic impact on rivers and riparian zones, mainly for energy and irrigation, was achieved by fragmenting the river courses through dams and channel diversions ${ }^{25}$, that led to a dramatic decrease in the supply of coarse-grained material to the sea (Fig. 4$)^{26}$. Due to sediment retention on anthropic reservoirs, the reduced riverine clastic input no longer balances the sink of delta plains caused by subsidence and sea level rise ${ }^{27}$. Delta systems become, therefore, more vulnerable to the action of marine processes, leading to a generalized phase of delta erosion and retreat. During the last five decades, several $\mathrm{km}^{2}$ of delta plains have been submerged and all northern Mediterranean and Black Sea deltas underwent extensive erosion (Supplementary S4). The same fate has been documented for deltaic systems worldwide where similar human impact has occurred $^{28,29}$.

\section{Discussion}

The quantitative comparison and correlation of the growth phases of the largest southern European deltas show that their outbuilding peaked almost simultaneously in two short intervals when human activities were at their maximum: the Roman Empire and Little Ice Age. These growth phases occurred during contrasting climatic conditions (dominantly warmer during the Roman Empire and cooler during the LIA). In both cases the anthropic control on the natural environments overshot the climatic signal forcing delta systems toward a man-made river-dominated signature. Both phases of man-made delta outbuilding were followed by discrete intervals of delta retreat caused by a dearth in sediment flux and, consequently, an increased effect of marine reworking. However, the two retreat phases, though similar in their impacts on deltas, have a markedly different origin: after the fall of the Roman Empire soil erosion was contrasted by a new afforestation phase and delta systems just relaxed to their background (pre-anthropic) natural equilibrium; on the contrary, during the last 50 years, Mediterranean and Black Sea deltas reflect the simultaneous increase in sediment production through soil erosion but yet reduced sediment flux to the coasts because of retention within reservoirs, fluvial regulation and excavation. The chronological constraints available for Mediterranean and Black Sea deltas indicate how natural systems respond "instantaneously" to human perturbation; this rapidity of response should be taken seriously into account in any management attempt of the coastal zone.

\section{Methods}

The data presented in this Manuscript are derived from a systematic scrutiny of up to 50 scientific papers and reports on Mediterranean and Black Sea deltas, available in national and international literature (Supplementary S3). The modern southern European deltas were intensively investigated during the last two decades by integrating subsurface (seismic sections and boreholes) and subaerial data (satellite images of delta plains), supported by sedimentological, paleoenvironmental and chronological constraints. The main phases of delta progradation derived by the literature were constrained chronologically by hundreds of radiocarbon and few tens of OSL dates. The resulting chronologies are integrated for the last few centuries by historical records, in the form of ancient maps and chronicles, that allowed independent estimates of the main constructional and retreat phases in each delta.

The averaged linear progradation rates presented here are quantified considering the three-dimensional nature of each delta system (Supplementary S1), and taking into account all the available regional paleoenvironmental constraints (climate, relative sea level oscillations, and oceanography, Supplementary S2).

1. Coleman, J. M. \& Wright, L. D. Modern river deltas; variability of processes and sand bodies. In: Broussard, M.L., (Eds.), Deltas; Models for Exploration, Houston Geological Society, Texas, pp. 99-149 (1975).

2. Galloway, W. E. Process framework for describing the morphologic and stratigraphic evolution of deltaic depositional systems. In: Broussard, M.L., (Eds.),
Deltas; Models for Exploration, Houston Geological Society, Texas, pp. 87-98 (1975).

3. Syvitski, J. P. M. \& Saito, Y. Morphodynamics of deltas under the influence of humans. Global and Planetary Change 57, 261-282 (2007).

4. Törnqvist, T. E. \& Hijma, M. P. Links between early Holocene ice-sheet decay, sealevel rise and abrupt climate change. Nature Geoscience 5, 601-606 (2012).

5. Stanley, J. D. \& Warne, A. G. Worldwide Initiation of Holocene Marine Deltas by Deceleration of Sea-Level Rise. Science 265, 228-231 (1994).

6. Bond, G. et al. Persistent Solar Influence on North Atlantic Climate During the Holocene. Science 294, 2130-2136 (2001).

7. Ruddiman, W. F. The Anthropogenic greenhouse era began thousands of years ago. Climate Change 61, 261-293 (2003).

8. Kennett, D. J. et al. Development and Disintegration of Maya Political Systems in Response to Climate Change. Science 338, 788-791 (2012).

9. Büntgen, U. et al. 2500 Years of European Climate Variability and Human Susceptibility. Science 331, 578-582 (2011).

10. Kobashi, T. et al. High variability of Greenland surface temperature over the past 4000 years estimated from trapped air in an ice core. Geophysical Research Letters 38, 1-6 (2011).

11. Olsen, J., Anderson, N. J. \& Knudsen, M. F. Variability of the North Atlantic Oscillation over the past 5,200 years. Nature Geoscience 5, 808-812 (2012).

12. Kaplan, J. O., Krumhardt, K. M. \& Zimmermann, N. The prehistoric and preindustrial deforestation of Europe. Quaternary Science Reviews 28, 3016-3034 (2009).

13. Hong, S., Candelone, J.-P., Patterson, C. C. \& Boutron, C. F. Greenland Ice Evidence of Hemispheric Lead Pollution Two Millennia Ago by Greek and Roman Civilizations. Science 265, 1841-1843 (1994).

14. Marriner, N. \& Morhange, C. Geoscience of ancient Mediterranean harbours. Earth-Science Reviews 80, 137-194 (2007).

15. Klein Goldewijk, K. Estimating global land use over the past 300 years: The HYDE Database. Global Biogeochemical Cycles 15, 417-433 (2001).

16. Trouet, V. et al. Persistent Positive North Atlantic Oscillation Mode Dominated the Medieval Climate Anomaly. Science 324, 78-80 (2009).

17. Mann, M. E. et al. Global Signature and Dynamical Origins of the Little Ice Age and Medieval Climate Anomaly. Science 326, 1256-1260 (2009).

18. Grove, J. M. \& Switsur, R. Glacial geological evidence for the Medieval Warm Period. Climatic Change 26, 143-169 (1994).

19. Holzhauser, H., Magny, M. \& Zumbühl, H. J. Glacier and Lake-level variations in west-central Europe over the last 3500 years. The Holocene 15, 789-801 (2005).

20. Tinner, W. et al. Climatic change and contemporaneous land-use phases north and south of the Alps $2300 \mathrm{BC}$ to $800 \mathrm{AD}$. Quaternary Science Reviews 22, 1447-1460 (2003).

21. Kuhlemann, J. et al. Regional Synthesis of Mediterranean Atmospheric Circulation During the Last Glacial Maximum. Science 321, 1338-1340 (2008).

22. Sahin, V. \& Hall, M. J. The effects of afforestation and deforestation on water yealds. Journal of Hydrology 178, 293-309 (1996).

23. Glaser, R. et al. The variability of European floods since AD 1500. Climatic Change 101, 235-256 (2010).

24. Vitousek, P. M., Mooney, H. A., Lubchenco, J. \& Melillo, J. M. Human domination of Earth's Ecosystems. Science 277, 494-499 (1997).

25. Dynesius, M. \& Nilsson, C. Fragmentation and flow regulation od river systems in the northern third of the World. Science 266, 753-762 (1994).

26. Syvitski, J. P. M., Vörösmarty, C. J., Kettner, A. J. \& Green, P. Impact of humans on the flux of terrestrial sediment to the global coastal ocean. Science 308, 376-380 (2005).

27. Syvitski, J. P. M. et al. Sinking deltas due to human activities. Nature Geoscience 2, 681-686 (2009).

28. Blum, M. D. \& Roberts, H. H. Drowning of the Mississippi Delta due to insufficient sediment supply and global sea-level rise. Nature Geoscience 2, 488-491 (2009).

29. Giosan, L. et al. Early anthropogenic transformation of the Abube-Black Sea systems. Scientific Reports 2, 1-6 (2012).

30. Tinner, W. et al. Fire ecology north and south of the Alps since the last ice age. The Holocene 15, 1214-1226 (2005).

31. Sorrel, P. et al. Persistent non-solar forcing of Holocene storm dynamics in coastal sedimentary archives. Nature Geoscience 5, 892-896 (2012).

\section{Acknowledgments}

This work has been funded by the Flagship Project RITMARE - The Italian Research for the Sea - coordinated by the Italian National Research Council and funded by the Italian Ministry of Education, University and Research within the National Research Program 2011-2013. This is ISMAR-Bologna contribution n. 1791.

\section{Author contributions}

V.M. analyzed and interpreted the data of delta progradation. V.M. and F.T. wrote the paper. 


\section{Additional information}

Supplementary information accompanies this paper at http://www.nature.com/ scientificreports

Competing financial interests:The authors declare no competing financial interests.
License: This work is licensed under a Creative Commons

Attribution-NonCommercial-NoDerivs 3.0 Unported License. To view a copy of this license, visit http://creativecommons.org/licenses/by-nc-nd/3.0/

How to cite this article: Maselli, V. \& Trincardi, F. Man made deltas. Sci. Rep. 3, 1926; DOI:10.1038/srep01926 (2013). 